\title{
The Nocebo Effect and Pediatric Concussion
}

\author{
Michael W. Kirkwood, David R. Howell, Brian L. Brooks, Julie C. Wilson, and William P. Meehan III
}

\begin{abstract}
While placebo effects are well recognized within clinical medicine, "nocebo effects" have received much less attention. Nocebo effects are problems caused by negative expectations derived from information or treatment provided during a clinical interaction. In this review, we examine how nocebo effects may arise following pediatric concussion and how they may worsen symptoms or prolong recovery. We offer several suggestions to prevent, lessen, or eliminate such effects. We provide recommendations for clinicians in the following areas: terminology selection, explicit and implicit messaging to patients, evidence-based recommendations, and awareness of potential biases during clinical interactions. Clinicians should consider the empirically grounded suggestions when approaching the care of pediatric patients with concussion.
\end{abstract}

Keywords: mild traumatic brain injury, rehabilitation, placebo effect, adolescents, symptomatology

The beliefs we have about medical conditions can affect the experience and outcome of the condition. This has been most clearly established for the placebo effect. Recognized in the medical literature since the 18th century, the placebo effect occurs when a patient's positive expectation that treatment will be beneficial results in a better outcome, even when, for example, the patient is given a sugar pill. ${ }^{1}$ Placebo effects are driven by both psychological and physiological processes and have been demonstrated across many different medical conditions. ${ }^{2}$ A systematic review documented clear placebo effects in adult patients who have sustained traumatic brain injury (TBI), including in high-quality randomized controlled trials demonstrating that placebo agents can have comparable effects to active medications in improving irritability, cognition, and mood. ${ }^{3}$

The flipside of placebo is nocebo. The nocebo effect was first described in the 1960s to refer fairly narrowly to negative side effects reported by patients who were given inert pills. ${ }^{4}$ In recent years, the nocebo effect has been conceptualized more broadly as problems caused by negative expectations derived from any health care information or treatment. The mere suggestion of a problem within the context of a medical condition may be enough to create the problem in a sort of "self-fulfilling prophecy" for the patient. Just like placebo, the nocebo effect is not solely a psychological process, as it is associated with changes in underlying physiology and pathology. ${ }^{5}$ At its most extreme, the phenomenon can be seen in cases of so-called "voodoo death," in which somebody is told they are cursed and will die and then actually dies. ${ }^{6}$

Kirkwood is with the Department of Physical Medicine \& Rehabilitation, University of Colorado School of Medicine, Aurora, CO, USA; and the Department of Rehabilitation Medicine, Children's Hospital Colorado, Aurora, CO, USA. Howell and Wilson are with the Sports Medicine Center, Children's Hospital Colorado, Aurora, CO, USA; and the Department of Orthopedics, University of Colorado School of Medicine, Aurora, CO, USA. Brooks is with the Departments of Pediatrics, Clinical Neurosciences, and Psychology, University of Calgary, Calgary, $\mathrm{AB}$, Canada; and the Alberta Children's Hospital Research Institute, University of Calgary, Calgary, AB, Canada. Wilson is also with the Department of Pediatrics, University of Colorado School of Medicine, Aurora, CO, USA. Meehan is with The Micheli Center for Sports Injury Prevention, Waltham, MA, USA; the Division of Sports Medicine, Boston Children's Hospital, Boston, MA, USA; and the Departments of Orthopedic Surgery and Pediatrics, Harvard Medical School, Boston, MA, USA. Howell (David.Howell@CUAnschutz.edu) is corresponding author.

\section{Nocebo and Pediatric Concussion}

Concussion, a brain injury at the mild end of the TBI spectrum, is caused by a direct blow to the head, face, neck, or body with an impulsive force transmitted to the brain, which results in a range of clinical signs and symptoms. ${ }^{7}$ Many high-quality research studies indicate that the majority of youth who sustain a concussion make an excellent clinical recovery, typically within hours to weeks. ${ }^{8}$ In contrast, a relatively high proportion of individuals seen in specialty clinics present with more significant symptomatology and disruption to quality of life. ${ }^{9}$ Injury-related variables (eg, severity of the concussion) can contribute to these postconcussive symptoms. ${ }^{10}$ However, many noninjury factors are known to influence the postconcussive symptom report as well, such as premorbid anxiety and somatization, maladaptive coping, parental anxiety, and symptom exaggeration/feigning. ${ }^{11}$ While both injury and noninjury factors account for variance relatively soon after concussion, noninjury factors account for much more variance when symptoms persist for many weeks to months. ${ }^{12}$

One noninjury factor that has received scant attention in the pediatric concussion literature is the nocebo effect. Yet, negative expectations, beliefs, and attitudes about concussion that youth and their families hold are likely to affect symptom experience, recovery course, and outcomes. Multiple adult studies have found that individuals who expect to recover more slowly after a concussion are more likely to do so. ${ }^{13}$ Additionally, suggesting to adults with TBI that they are more likely to have cognitive challenges as a result of their injury has been found to result in greater cognitive problems on objective neuropsychological testing, ${ }^{14}$ fulfilling the negative expectation associated with a nocebo effect. Conversely, brief psychoeducation providing reassurance soon after injury can improve outcomes. ${ }^{15}$

The amount of information available about concussion has grown exponentially in the last 20 years, both in the scientific literature and in the popular media. Discerning the scientific validity of the rapidly evolving concussion literature is challenging, in part because of the sheer volume of information now available. As a result, a potential nocebo effect may exist from biased perceptions and beliefs about concussive injuries based on information unsupported by empirically driven research. ${ }^{16}$ In fact, misrepresentation in the media has resulted in the public perception 
of concussion as more negative than the perception within the medical community itself. ${ }^{3,16}$ Well-meaning health care providers, athletic personnel, and school personnel may inadvertently perpetuate misinformed beliefs if they are not aware of the current recommendations and evidence related to concussion. Examples of mistaken beliefs abound.

For instance, some people believe that a minor head impact can lead to a loss of autobiographical memory (eg, "Gilligan Island's amnesia" whereby a coconut falling on the head in the 1960s television series led to characters losing their memory of who they were). Although brief memory loss for events around the time of the injury can occur with concussion, in actuality, no data support the notion that well-established knowledge and skills (eg, knowing who we are, who our family and friends are, or how to read or do math in older children) are directly affected by concussion. Another mistaken idea is that the way to treat concussion is through absolute "brain rest" (eliminating television, phone, socialization, school work, etc). No clinical trials have supported this idea and recent work suggests that too much rest is actually apt to increase (worsen), rather than decrease (improve), reported symptomatology. ${ }^{17}$ In another example, participation in contact sports is now thought by some to have a relatively high risk of death or to lead inexorably to dementia or suicide. ${ }^{18}$ In fact, death from sportrelated head trauma is extremely rare, less frequent than death by lightning strike. ${ }^{19}$ Despite nearly universal media coverage to the contrary, the link between sports and adverse long-term cognitive and psychiatric outcomes, including the pathological entity known as Chronic Traumatic Encephalopathy, has not yet been causally established, and studies examining exposure to repeated sportrelated head trauma early in life do not consistently support an effect. ${ }^{7,20-23}$ Furthermore, population-based studies of older adults who played high school football have not found higher rates of neurodegenerative diseases or worse neurocognitive outcomes relative to the general population. ${ }^{24-26}$

The role of the media in the spread of misinformation is apparent in much of the sensationalistic concussion coverage that has appeared of late. Commonly available concussion information often contains inaccurate information. ${ }^{27}$ The role of wordof-mouth communication in the spread of misinformation is less obvious but is still one avenue likely responsible for some nocebo effects, particularly among schools, athletic clubs, and other relatively small social circles. The pain literature provides a nice illustration of how this could happen. In one study, researchers in Italy recruited 121 medical students to purportedly examine the effects of altitude. ${ }^{28}$ They told a single participant about the possible occurrence of severe headache at high altitude. Within a week, this information had spread from the single individual to 36 participants. Then, the researchers took all the students to high altitude, where those who had heard this information were significantly more likely to report severe headache than those who had not. In a similar manner, social circles among patients, friends, and families may influence expectations about symptoms and recovery following concussion.

\section{Implications for Concussion Clinical Management}

The importance of understanding nocebo phenomena in the clinical management of concussion cannot be overstated. Increased symptomatology, anxiety, hypervigilance, and worsened outcomes overall may occur if providers contribute to negative expectations in their clinical discussions. Most patients place great value on the opinions of their doctors. In turn, doctors can feel some pressure to know "the answers" and to do "something" when a patient or family is suffering. ${ }^{29}$ Quality of life for patients and families with persistent postconcussive symptoms can indeed be quite poor. ${ }^{30}$ However, in many cases, clear-cut medical explanations for the apparent problems are lacking, and few interventions have been established empirically to treat the problems. This results in a situation where providers may overmanage in an attempt to help, paradoxically worsening rather than improving, outcomes.

\section{What Can Providers do to Prevent, Lessen, And Eliminate Nocebo Effects?}

\section{Choose Terms Carefully}

In the experimental pain literature, the more frequently used terms, such as "hurt," "burn," and "sting" are used, the more discomfort a person reports. ${ }^{31}$ In the context of concussion, the terminology used during discussions about the injury almost certainly affects symptom experience as well.

- When discussing the term concussion, explain that it is generally considered to be a mild injury that temporarily disrupts the brain's functioning rather than injury that results in permanent structural damage.

- Avoid the term "postconcussion syndrome." It is scientifically controversial, poorly defined, and of questionable diagnostic value. ${ }^{32}$ The term "syndrome" also likely implies for many that the symptoms being experienced cluster in a well-established fashion that results directly from the concussion, which is most typically not the case. Less nocebo-laden options include a factual description such as "persistent postconcussion symptoms" " or in International Classification of Diseases (ICD)-10 diagnostic language something like, "concussion without loss of consciousness, subsequent encounter."

- Avoid the term "second impact syndrome," which again may not be a true syndrome and has not been supported in systematic analyses. ${ }^{33}$ Catastrophic outcomes from cerebral trauma can happen in sports, albeit rarely. However, the vast majority of catastrophic outcomes are not caused by isolated cerebral edema from back-to-back concussions as is purported in second impact syndrome. Malignant cerebral edema is a well-documented phenomenon after minor head injury, with numerous reported cases in the pediatric neurosurgical literature. In the sports literature, McCrory and Berkovic ${ }^{34}$ also identified a dozen cases of unexplained cerebral swelling, although none had evidence of a second impact as the triggering event. Randolph and Kirkwood ${ }^{35}$ also systematically analyzed catastrophic outcomes at all levels of American football across a 10-year period. During the period, cerebral injury resulted in 38 deaths, with the vast majority occurring in high school athletes from acute subdural hematoma. Only a single death was attributed to diffuse cerebral swelling, which would translate to a risk of 1 event for every 18 million player seasons. If second impact syndrome exists at all, it is exceedingly rare, despite the influence the idea has had in clinical management and in the development of some historic sports concussion guidelines. 


\section{Be Thoughtful About Messaging, Both Explicit and Implicit}

- One goal of messaging after concussion is to set the stage for a positive recovery and avoid contributing to negative expectations.

- Provide education about the typical short-lived recovery course, particularly during the acute and subacute postinjury stage, when expectations are most easily shaped. While the exact timing of individual recovery can be difficult to predict, clinicians can explain that typical recovery occurs within a few days to a few weeks for the majority of children and adolescents. ${ }^{8,36}$ Terminology referring to persistent symptoms should be reserved for those patients whose recovery extends beyond the typical timeframe. ${ }^{8}$

- In the first days to weeks after injury, explain what symptoms are commonly experienced by pediatric patients after a concussion, ${ }^{37}$ and reassure that symptoms are not uncommon.

- Describe that "postconcussive" symptoms are not specific to concussion, as they overlap with symptoms brought on by other conditions or circumstances related to the injury (eg, anxiety, stress, physical inactivity, academic concerns, poor sleep, neck pain). ${ }^{17,38-41}$

- In the face of symptom flare-ups, reassure that, these are not unusual and does not mean the brain has been damaged, in the absence of a structural brain injury. ${ }^{42}$ Similarly, reassure that if the transition back to typical activities is associated with some worsening of symptoms, this can be expected to be temporary and, again, will not damage the brain.

- Acknowledge that a concussion can temporarily disrupt the typical routine and daily activities for some children and adolescents, ${ }^{43}$ but highlight the importance of partnership with the medical and school teams to help facilitate recovery. Let the family know that the role of the clinician is to help until the situation returns to normal and what the plan for follow-up or referral will be.

- In the face of symptom persistence and/or significant functional disruption, empathic validation of the patient and family experience is important. Subsequent normalization (eg, "we have seen similar presentations countless times in our program") can then be helpful to reassure the family that their experience is neither extreme nor unique and that there is reason to expect improvement. Discussion about how noninjury factors (eg, stress) often play a role in these instances is also usually indicated, along with how these factors will be addressed (eg, psychological intervention, short-lived school adjustments). Providing academic and psychological support when needed during recovery is important, as academic and mood concerns have been associated with persistent symptoms. ${ }^{44}$ Failure to treat these contributing factors may lead to continuing symptoms erroneously being attributed to the persistent pathophysiology of concussion.

- If a discussion about sport-related catastrophic outcomes is warranted, be sure to put this in proper context and clearly emphasize its rarity.

- If a discussion about the potential long-term effects of repeated concussion is warranted, place the risk in context related to what is known and not known at this stage in the research. ${ }^{45}$ Discuss studies on which current hypotheses are based, and the limitations of these studies ${ }^{46}$ Facilitate the process of weighing the potential risks associated with concussions against the benefits of participating in sports. Discussion about the role of protective equipment and measures to reduce the risk of concussion may also be reasonable, ${ }^{47}$ although families should understand that there is no method of completely preventing concussions.

\section{Remember That "More" is Not Always Better When it Comes to Intervention}

In a largely nonevidence-based intervention environment, the risk of overmanaging problems and contributing to nocebo effects is high. Of course, the first step in concussion clinical management is to ensure patient safety, which includes ruling out medical explanations for apparent problems (eg, more severe neurologic injury) and guiding a safe return to higher risk activities such as contact sports. More generally, recommendations should avoid reinforcing negative expectations and beliefs.

- No vitamins, supplements, or medications have been shown to substantially improve concussion recovery. ${ }^{46,48}$ Melatonin is commonly suggested to improve sleep after concussion, although a recent randomized, double-blind trial did not find support for its use in a pediatric sample (Karen M). ${ }^{49}$ In children and adolescents, there are also questions about the efficacy and risk-benefit profile of commonly used prescription medications for symptoms of concussion (eg, headaches). ${ }^{50}$ With this in mind, starting with minimally invasive interventions is sensible, as these are less apt to be associated with negative physical or psychological side effects. For example, before recommending a medication to improve sleep, one could focus on sleep hygiene, psychoeducation, or psychotherapy ${ }^{41}$; before trying a prescription headache medication, one could try diet recommendations or more benign over-thecounter medications.

- Avoid nonevidence-based interventions that may help perpetuate the idea that the child is seriously unwell. Many interventions that are purported to be concussion treatments are conceptually not sensible and lack evidentiary grounding. They also often, subtly, or not so subtly, reinforce negative expectations for the youth and family. Some can externally signal to others that the youth is more severely "brain injured," which can change social reinforcements and promote the adoption of such a persona by the youth. Examples here would include encouraging the youth to use a walking cane, prism glasses, sunglasses indoors, or noise canceling headphones.

- Avoid recommending strict or long-term rest, neither of which is empirically backed and both of which often implicitly send the message that the injury is more severe than is actually the case. ${ }^{17,42}$ For example, being told to not do something as benign as watching television or sending a text can clearly conjure up the wrong idea about injury severity by the patient and family..$^{51}$ Furthermore, the incorporation of aerobic activity during concussion recovery has been increasingly promoted in recent years to aid recovery and reduce persistent symptoms. ${ }^{52,53}$

- Recommend approaches that reinforce and support the return to typical activities and functioning, such as regular exercise, that does not exacerbate symptoms, full-time school reintegration, and typical social and other recreational activities. ${ }^{54}$ Behavioral prescription for a gradual "return to life," as well as referral to Physical Therapy when indicated, can be helpful in this regard, as they can support the patient during initial symptomatology, but simultaneously communicate the expectation that return to normalcy is expected. ${ }^{55-58}$ 
- Education-related recommendations are often needed to support difficulties that commonly disrupt school performance such as headaches, inattention, fogginess, and so forth. One important message to provide to families and school personnel as part of these recommendations is that these concussion supports will only need to be in place temporarily, as a full recovery is expected. In the overwhelming number of cases, long-lasting Section 504 plans and special education plans (Individualized Education Programs) are not needed for concussion-specific problems.

\section{Stay Abreast of the Most Recent Research and Evidence-Based Recommendations}

Proper health care is contingent on lifelong learning from reliable, medical sources. The nocebo effect often results from well-meaning practitioners who simply continue to make recommendations grounded in outdated knowledge or reflect reports they have heard in the lay media as opposed to the medical literature. As mentioned, there was never evidence for "absolute" or "prolonged" physical rest, ${ }^{59,60}$ yet this recommendation is still frequently encountered in clinical settings. All health care providers caring for youth with mild TBI should practice within their areas of competence, take accredited continuing education courses within the broad field of concussion, critically read research literature on concussion outcomes and treatment, and rely heavily on evidence-based reviews and recommendations. ${ }^{54}$

Be aware of potential biases during clinical interactions. Biases are part of human nature and can readily influence clinical judgment. ${ }^{61}$ When working with children and families after concussion, clinicians should be aware of potential biases that can occur and minimize these biases in their interactions. Below are some common biases and logical misconceptions that can influence how clinicians gather information and make decisions about concussion management, which can increase the risk for nocebo effects.

- Confirmatory/confirmation bias. Humans search for and retain information that confirms their preconceived notions and beliefs in the world and tend to avoid or disregard information that goes against what they already believe to be true. These confirmation biases often cause clinicians to test hypotheses that align with their beliefs (and fail to test hypotheses that go against their beliefs). They are readily influenced by confirmatory pieces of information (eg, anchoring their opinion based on a referral sent to them that a patient has persistent symptoms and is not improving) and often assume that 2 events occurring around the same time (eg, concussion and academic decline) are causally related even in the absence of supportive and conclusive literature. ${ }^{62}$ They then adjust decisions or opinions to fit the data that are collected instead of using the data to accept or refute a hypothesis (ie, a clustering illusion). Past work ${ }^{63}$ provides suggestions for how to reduce biases. The general approach for reducing confirmatory biases involves starting with the most valid information, listing alternatives, and seeking both confirmatory and disconfirmatory information.

- Failure to appreciate base rates. Appreciating the probability of an event occurring is essential to establishing an accurate clinical opinion and minimizing nocebo effects. When children sustain concussions, it is well known that the vast majority will recover symptomatically. For example, a largescale, pan-Canadian, pediatric cohort study suggested that
$30 \%$ of children will have persistent symptoms for more than 1 month postconcussion ${ }^{8}$; however, this should also be read as $70 \%$ will not have symptoms for more than 1 month (and it also must be remembered that persistent symptoms are often related to noninjury factors). When a child sustains a concussion, 4 out of 5 times it would be correct to tell the patient "you will recover within about 1 month" without any further knowledge about the patient. Additional epidemiological research has suggested that persistent postconcussion symptoms are found in $11 \%$ of youth at 3 months and $2 \%$ of youth at 1 year (Karen Maria). ${ }^{64}$ This means that the probability of persistent postconcussion symptoms occurring long after an injury is far lower than the probability of recovery, and failure to communicate the higher probability of recovery is more likely to lead to a nocebo effect.

- Good old days bias. The idea behind the "good old days" bias is that after a negative event (eg, concussion) people remember themselves as healthier and functioning better before the event than they actually were and do not recall common problems they had experienced. ${ }^{65}$ There have been numerous studies demonstrating that retrospective recall of concussion symptoms is highly influenced by this bias, leading to a misattribution that current symptoms are due to the concussion rather than being preexisting. ${ }^{66-68}$ One study within a pediatric concussion population recruited through the emergency department found that a clinician is 5 to 7 times more likely to falsely conclude the presence of persistent postconcussion symptoms when relying on retrospective symptom ratings at a follow-up visit (compared with preinjury symptoms obtained in the emergency department around the time of injury). ${ }^{69}$ This "good old days" bias means that clinicians must use caution when trying to determine preinjury status based on self- or parent-report (or avoid this comparison all together) for the risk of a nocebo effect is substantial.

\section{Conclusion}

In summary, when managing pediatric concussion, a nocebo effect can occur in a number of areas. Much like the positive aspects of the placebo effect can be useful for a clinician to help a patient recover, the nocebo effect can result in worsening of symptoms and prolonged recovery time. Carefully choosing terminology, being thoughtful about messaging, emphasizing expected outcomes, providing appropriate support during recovery, and being aware of and reducing common human biases are all important considerations to help minimize or eliminate potential nocebo effects and facilitate patient recovery. Clinicians should consider the above empirically grounded suggestions when approaching the care of pediatric patients with concussion. Furthermore, clinicians should act knowledgeably, responsibly, and truthfully, when discussing concussion with their patients and the media.

\section{Acknowledgments}

None of the authors received financial support for writing this manuscript. Dr M.W.K. has received reimbursement and honoraria from multiple professional organizations for presentations related to pediatric TBI. He has received research funding from governmental agencies for projects focused on pediatric TBI. He receives royalties from Guilford Press and Oxford University Press for the sale of 3 scientific books that he has edited that cover TBI-related topics: (1) Mild Traumatic Brain Injury in Children and Adolescents, (2) Validity Testing in Child and Adolescent Assessment, 
and (3) Neuropsychology Study Guide \& Board Review (First and Second Editions). Dr D.R.H. has received research support from the Eunice Kennedy Shriver National Institute of Child Health and Human Development (R03HD094560), the National Institute of Neurological Disorders and Stroke (R01NS100952, R03HD094560, and R43NS108823), the MINDSOURCE Brain Injury Network, and the Tai Foundation. Dr W.P.M. receives royalties from (1) ABC-Clio publishing for the sale of his books, Kids, Sports, and Concussion: A guide for coaches and parents, and Concussions; (2) Springer International for the book Head and Neck Injuries in the Young Athlete; and (3) Wolters Kluwer for working as an author for UpToDate. His research is funded, in part, by philanthropic support from the National Hockey League Alumni Association through the Corey C. Griffin Pro-Am Tournament and a grant from the National Football League. Dr B.L.B. receives royalties for the sales of the Pediatric Forensic Neuropsychology textbook (2012, Oxford University Press) and 3 pediatric neuropsychological tests (Child and Adolescent Memory Profile [ChAMP, Sherman and Brooks, ${ }^{70}$ PAR Inc], Memory Validity Profile [MVP, Sherman and Brooks, ${ }^{71}$ PAR Inc], and Multidimensional Everyday Memory Ratings for Youth [MEMRY, Sherman and Brooks, ${ }^{72}$ PAR Inc]). His research program is supported by the Canadian Institutes of Health Research Embedded Clinician Researcher Award.

\section{References}

1. Beecher HK. The powerful placebo. J Am Med Assoc. 1955; 159(17):1602-1606. PubMed ID: 13271123 doi:10.1001/jama. 1955.02960340022006

2. Diederich NJ, Goetz CG. The placebo treatments in neurosciences: new insights from clinical and neuroimaging studies. Neurology. 2008;71(9):677-684. PubMed ID: 18725593 doi:10.1212/01.wnl. 0000324635.49971.3d

3. Polich G, Iaccarino MA, Kaptchuk TJ, Morales-Quezada L, Zafonte R. Placebo effects in traumatic brain injury. J Neurotrauma. 2018; 35(11):1205-1212. doi:10.1089/neu.2017.5506

4. Kennedy WP. The nocebo reaction. Med World. 1961;95:203-205. PubMed ID: 13752532

5. Benedetti F, Piedimonte A. The neurobiological underpinnings of placebo and nocebo effects. Semin Arthritis Rheum. 2019;49(3S): S18-S21. PubMed ID: 31779844 doi:10.1016/j.semarthrit.2019.09.015

6. Lester D. Voodoo death. Omega. 2009;59(1):1-18. PubMed ID: 19634503 doi:10.2190/OM.59.1.a

7. McCrory P, Meeuwisse W, Dvorak J, et al. Consensus statement on concussion in sport - the 5th international conference on concussion in sport held in Berlin, October 2016. Br J Sports Med. 2017; 51(11):838-847. doi:10.1136/bjsports-2017-097699

8. Zemek R, Barrowman N, Freedman SB, et al. Clinical risk score for persistent postconcussion symptoms among children with acute concussion in the ED. JAMA. 2016;315(10):1014-1025. PubMed ID: 26954410 doi:10.1001/jama.2016.1203

9. Corwin DJ, Zonfrillo MR, Master CL, et al. Characteristics of prolonged concussion recovery in a pediatric subspecialty referral population. J Pediatr. 2014;165(6):1207-1215. doi:10.1016/j.jpeds. 2014.08.034

10. Yeates KO, Taylor HG, Rusin J, et al. Longitudinal trajectories of postconcussive symptoms in children with mild traumatic brain injuries and their relationship to acute clinical status. Pediatrics. 2009;123(3): 735-743. PubMed ID: 19254996 doi:10.1542/peds.2008-1056

11. Kirkwood MW, Peterson RL, Connery AK, Baker DA, Grubenhoff JA. Postconcussive symptom exaggeration after pediatric mild traumatic brain injury. Pediatrics. 2014;133(4):643-650. PubMed ID: 24616360 doi:10.1542/peds.2013-3195
12. McNally KA, Bangert B, Dietrich A, et al. Injury versus noninjury factors as predictors of postconcussive symptoms following mild traumatic brain injury in children. Neuropsychology. 2013;27(1): 1-12. PubMed ID: 23356592 doi:10.1037/a0031370

13. Vanderploeg RD, Belanger HG, Kaufmann PM.. Nocebo effects and mild traumatic brain injury: legal implications. Psychol Injury Law. 2014;7(3):245-254. doi:10.1007/s12207-014-9201-3

14. Suhr JA, Gunstad J. "Diagnosis Threat": the effect of negative expectations on cognitive performance in head injury. J Clin Exper Neuropsychol. 2002;24(4):448-457. PubMed ID: 12187458 doi:10. 1076/jcen.24.4.448.1039

15. Mittenberg W, Canyock EM, Condit D, Patton C. Treatment of postconcussion syndrome following mild head injury. J Clin Exper Neuropsychol. 2001;23(6):829-836. PubMed ID: 11910547 doi:10. 1076/jcen.23.6.829.1022

16. Block CK, West SE, Goldin Y. Misconceptions and misattributions about traumatic brain injury: an integrated conceptual framework. PM R. 2016;8(1):58-68.e4. doi:10.1016/j.pmrj.2015.05.022

17. Thomas DG, Apps JN, Hoffmann RG, McCrea M, Hammeke T. Benefits of strict rest after acute concussion: a randomized controlled trial. Pediatrics. 2015;135(2):213-223. PubMed ID: 25560444 doi:10.1542/peds.2014-0966

18. Iverson GL. Retired national football league players are not at greater risk for suicide. Arch Clin Neuropsychol. 2019;35(3):332-341. doi:10.1093/arclin/acz023

19. Kirkwood MW, Randolph C, Yeates KO. Sport-related concussion: a call for evidence and perspective amidst the alarms. Clin J Sport Med. 2012;22(5):383-384. doi:10.1097/JSM.0b013e31826396fc

20. Brett BL, Huber DL, Wild A, Nelson LD, McCrea MA. Age of first exposure to American football and behavioral, cognitive, psychological, and physical outcomes in high school and collegiate football players. Sports Health. 2019;11(4):332-342. PubMed ID: 31173699 doi: $10.1177 / 1941738119849076$

21. Caccese JB, DeWolf RM, Kaminski TW, et al. Estimated age of first exposure to American football and neurocognitive performance amongst NCAA male student-athletes: a cohort study. Sports Med. 2019;49(3):477-487. doi:10.1007/s40279-019-01069-x

22. Iverson GL, Gardner AJ, Shultz SR, et al. Chronic traumatic encephalopathy neuropathology might not be inexorably progressive or unique to repetitive neurotrauma. Brain. 2019;142(12):3672-3693. doi:10.1093/brain/awz286

23. Stewart W, Allinson K, Al-Sarraj S, et al. Primum non nocere: a call for balance when reporting on CTE. Lancet Neurol. 2019;18(3):231233. PubMed ID: 30784550 doi:10.1016/S1474-4422(19)30020-1

24. Deshpande SK, Hasegawa RB, Rabinowitz AR, et al. Association of playing high school football with cognition and mental health later in life. JAMA Neurol. 2017;74(8):909-918. PubMed ID: 28672325 doi:10.1001/jamaneurol.2017.1317

25. Janssen PHH, Mandrekar J, Mielke MM, et al. High school football and late-life risk of neurodegenerative syndromes, 1956-1970. Mayo Clin Proc. 2017;92(1):66-71. doi:10.1016/j.mayocp.2016.09.004

26. Savica R, Parisi JE, Wold LE, Josephs KA, Ahlskog JE. High school football and risk of neurodegeneration: a community-based study. Mayo Clin Proc. 2012;87(4):335-340. doi:10.1016/j.mayocp.2011. 12.016

27. Kollia B, Basch CH, Mouser C, Deleon AJ. Assessment of information on concussion available to adolescents on social media. Int J Prev Med. 2018;9:19. doi:10.4103/ijpvm.IJPVM_265_17

28. Benedetti F, Durando J, Vighetti S. Nocebo and placebo modulation of hypobaric hypoxia headache involves the cyclooxygenase-prostaglandins pathway. Pain. 2014; 55(5):921-928. doi:10.1016/j.pain. 2014.01.016 
29. Moynihan R, Doust J, Henry D. Preventing overdiagnosis: how to stop harming the healthy. BMJ. 2012;344:e3502. doi:10.1136/bmj. e3502

30. Fineblit S, Selci E, Loewen H, Ellis M, Russell K. Health-related quality of life after pediatric mild traumatic brain injury/concussion: a systematic review. J Neurotrauma. 2016;33(17):1561-1568. doi:10. 1089/neu.2015.4292

31. Blasini M, Corsi N, Klinger R, Colloca L. Nocebo and pain: an overview of the psychoneurobiological mechanisms. Pain Rep. 2017; 2(2). doi:10.1097/PR9.0000000000000585

32. Silverberg ND, Iverson GL. Etiology of the post-concussion syndrome: physiogenesis and psychogenesis revisited. NeuroRehab. 2011;29(4):317-329. PubMed ID: 22207058 doi:10.3233/NRE2011-0708

33. McCrory P, Davis G, Makdissi M. Second impact syndrome or cerebral swelling after sporting head injury. Curr Sports Med Rep. 2012;11(1):21-23. PubMed ID: 22236821 doi:10.1249/JSR.0b013e $3182423 \mathrm{bfd}$

34. McCrory PR, Berkovic SF. Second impact syndrome. Neurology. 1998;50:677-683. PubMed ID: 9521255 doi:10.1212/wnl.50.3.677

35. Randolph C, Kirkwood MW. What are the real risks of sport-related concussion, and are they modifiable? J Int Neuropsychol Soc. 2009;15(4):512-520. PubMed ID: 19573269 doi:10.1017/S1355617 $70909064 X$

36. Meehan WP, 3rd, d'Hemecourt P, Collins CL, Comstock RD. Assessment and management of sport-related concussions in United States high schools. Am J Sports Med. 2011;39(11):2304-2310. PubMed ID: 21969181 doi:10.1177/0363546511423503

37. Kerr ZY, Zuckerman SL, Wasserman EB, Covassin T, Djoko A, Dompier TP. Concussion symptoms and return to play time in youth, high school, and college American football athletes. JAMA Pediatr. 2016;170(7):647-653. PubMed ID: 27135397 doi:10.1001/ jamapediatrics.2016.0073

38. Brooks BL, Sayers PQ, Virani S, Rajaram AA, Tomfohr-Madsen L. Insomnia in adolescents with slow recovery from concussion. J Neurotrauma. 2019;36(16):2391-2399. doi:10.1089/neu.2018.6257

39. Howell DR, Potter MN, Provance AJ, Wilson PE, Kirkwood MW, Wilson JC. Sleep Problems and Melatonin Prescription After Concussion Among Youth Athletes. Clin J Sport Med. 2020. doi:10.1097/ JSM.0000000000000803

40. Provance AJ, Howell DR, Potter MN, Wilson PE, D'Lauro AM, Wilson JC. Presence of neck or shoulder pain following sportrelated concussion negatively influences recovery. J Child Neurol. 2020;35(7):456-462. PubMed ID: 32192408 doi:10.1177/0883073 820909046

41. Tomfohr-Madsen L, Madsen JW, Bonneville D, et al. A pilot randomized controlled trial of cognitive-behavioral therapy for insomnia in adolescents with persistent postconcussion symptoms. J Head Trauma Rehab. 2020;35(2):E103-E112. PubMed ID: 31246882 doi:10.1097/HTR.0000000000000504

42. Silverberg ND, Iverson GL, McCrea M, Apps JN, Hammeke TA, Thomas DG. Activity-related symptom exacerbations after pediatric concussion. JAMA Pediatr. 2016;170(10):946-953. PubMed ID: 27479847 doi:10.1001/jamapediatrics.2016.1187

43. Stein CJ, MacDougall R, Quatman-Yates CC, et al. Young athletes' concerns about sport-related concussion: the patient's perspective. Clin J Sport Med. 2016;26(5):386-390. doi:10.1097/JSM.00000000 00000268

44. Rieger B, Lewandowski L, Potts H, Shea N. Effects of concussion in adolescent students: perceptions and performance. J Int Neuropsychol Soc. 2019;25(8):777-786. PubMed ID: 31134869 doi:10.1017/ S1355617719000468
45. Harmon KG, Clugston JR, Dec K, et al. American medical society for sports medicine position statement on concussion in sport. Br J Sports Med. 2019;53(4):213-225. doi:10.1136/bjsports-2018-100338

46. Schneider KJ, Leddy JJ, Guskiewicz KM, et al. Rest and treatment/ rehabilitation following sport-related concussion: a systematic review. Br J Sports Med. 2017;51(12):930-994. doi:10.1136/ bjsports-2016-097475

47. Benson BW, Hamilton GM, Meeuwisse WH, McCrory P, Dvorak J. Is protective equipment useful in preventing concussion? A systematic review of the literature. Br J Sports Med. 2009;43(suppl 1): i56-i67. doi:10.1136/bjsm.2009.058271

48. Feinberg C, Carr C, Zemek R, et al. Association of pharmacological interventions with symptom burden reduction in patients with mild traumatic brain injury: a systematic review. JAMA Neurol. 2021. doi:10.1001/jamaneurol.2020.5079

49. Barlow KM, Brooks BL, Esser MJ, et al. Efficacy of melatonin in children with postconcussive symptoms: a randomized clinical trial. Pediatrics. 2020;145(4):e20192812. doi:10.1542/peds.2019-2812

50. Powers SW, Coffey CS, Chamberlin LA, et al. Trial of amitriptyline, topiramate, and placebo for pediatric migraine. $N$ Engl J Med. 2017;376(2):115-124. doi:10.1056/NEJMoa1610384

51. DiFazio M, Silverberg ND, Kirkwood MW, Bernier R, Iverson GL. Prolonged activity restriction after concussion: are we worsening outcomes? Clin Pediatr. 2015;55(5):443-451. doi:10.1177/000992 2815589914

52. Grool AM, Aglipay M, Momoli F, et al. Association between early participation in physical activity following acute concussion and persistent postconcussive symptoms in children and adolescents. JAMA. 2016;316(23):2504-2514. PubMed ID: 27997652 doi:10. 1001/jama.2016.17396

53. Leddy JJ, Haider MN, Ellis MJ, et al. Early subthreshold aerobic exercise for sport-related concussion: a randomized clinical trial. JAMA Pediatr. 2019;173(4):319-325. PubMed ID: 30715132 doi:10.1001/jamapediatrics.2018.4397

54. Lumba-Brown A, Yeates KO, Sarmiento K, et al. Centers for disease control and prevention guideline on the diagnosis and management of mild traumatic brain injury among children. JAMA Pediatr. 2018; e182853-e182853. doi:10.1001/jamapediatrics.2018.2853

55. Alsalaheen BA, Mucha A, Morris LO, et al. Vestibular rehabilitation for dizziness and balance disorders after concussion. J Neurol Phys Ther. 2010;34(2):87-93. PubMed ID: 20588094 doi:10.1097/NPT. 0b013e3181dde568

56. Collins MW, Kontos AP, Reynolds E, Murawski CD, Fu FH. A comprehensive, targeted approach to the clinical care of athletes following sport-related concussion. Knee Surg Sports Traumatol Arthrosc. 2014;22(2):235-246. PubMed ID: 24337463 doi:10. 1007/s00167-013-2791-6

57. Schneider KJ, Meeuwisse WH, Barlow KM, Emery CA. Cervicovestibular rehabilitation following sport-related concussion. $\mathrm{Br} J$ Sports Med. 2017;52(2):100-101. doi:10.1136/bjsports-2017098667

58. Schneider KJ, Meeuwisse WH, Nettel-Aguirre A, et al. Cervicovestibular rehabilitation in sport-related concussion: a randomised controlled trial. Br J Sports Med. 2014;48(17):1294-1298. doi:10. 1136/bjsports-2013-093267

59. DeMatteo C, Bednar ED, Randall S, Falla K. Effectiveness of return to activity and return to school protocols for children postconcussion: a systematic review. BMJ Open Sport Exerc Med. 2020;6(1):e000667. PubMed ID: 32153982 doi:10.1136/bmjsem2019-000667

60. Silverberg ND, Otamendi T, Panenka WJ, et al. De-implementing prolonged rest advice for concussion in primary care settings: a pilot 
stepped wedge cluster randomized trial. J Head Trauma Rehab. 2020;36(2):79-86. doi:10.1097/HTR.0000000000000609

61. Plourde V, Kung JY, Gates A, Jun S, Brooks BL, Sebastianski M. How perceptions impact recovery from concussion in childhood and adolescence: a systematic review. Neuropsychol Rev. 2020;30(1): 142-163. PubMed ID: 32124152 doi:10.1007/s11065-020-09430-y

62. Neelakantan M, Ryali B, Cabral MD, Harris A, McCarroll J, Patel DR. Academic performance following sport-related concussions in children and adolescents: a scoping review. Int J Environ Res Public Health. 2020;17(20). doi:10.3390/ijerph17207602

63. Wedding D, Faust D. Clinical judgment and decision making in neuropsychology. Archiv Clin Neuropsychol. 1989;4(3):233-265.

64. Barlow KM, Crawford S, Stevenson A, Sandhu SS, Belanger F, Dewey D. Epidemiology of postconcussion syndrome in pediatric mild traumatic brain injury. Pediatrics. 2010;126(2):e374-381. PubMed ID: 20660554 doi:10.1542/peds.2009-0925

65. Gunstad J, Suhr JA. "Expectation as etiology" versus "the good old days": postconcussion syndrome symptom reporting in athletes, headache sufferers, and depressed individuals. J Int Neuropsychol Soc. 2001;7(3):323-333. PubMed ID: 11311033 doi:10.1017/s1355 617701733061

66. Iverson GL, Lange RT, Brooks BL, Rennison VLA. "Good old days" bias following mild traumatic brain injury. Clin Neuropsychol.
2010;24(1):17-37. PubMed ID: 19830628 doi:10.1080/13854040 903190797

67. Voormolen DC, Cnossen MC, Spikman J, et al. Rating of pre-injury symptoms over time in patients with mild traumatic brain injury: the good-old-days bias revisited. Brain Injury. 2020;34(8):1001-1009. PubMed ID: 32567367 doi:10.1080/02699052.2020.1761563

68. Yang C.-C, Yuen K.-M, Huang S.-J, Hsiao S.-H, Tsai Y.-H, Lin W.-C. "Good-old-days" bias: a prospective follow-up study to examine the preinjury supernormal status in patients with mild traumatic brain injury. J Clin Exp Neuropsychol. 2014;36(4):399-409. PubMed ID: 24702428 doi:10.1080/13803395.2014.903899

69. Brooks BL, Kadoura B, Turley B, Crawford S, Mikrogianakis A, \& Barlow KM. Perception of recovery after pediatric mild traumatic brain injury is influenced by the "good old days" bias: tangible implications for clinical practice and outcomes research. Arch Clin Neuropsychol. 2014;29(2):186-193. doi:10.1093/arclin/act083

70. Sherman EMS, Brooks BL. Child and Adolescent Memory Profile (ChAMP). Lutz, FL: Psychological Assessment Resources, Inc; 2015.

71. Sherman EMS, Brooks BL. Memory Validity Profile (MVP). Lutz, FL: Psychological Assessment Resources, Inc; 2015.

72. Sherman EMS, Brooks BL. Multidimensional Everyday Memory Ratings for Youth (MEMRY). Lutz, FL: Psychological Assessment Resources, Inc; 2017. 